\title{
DIREITO HUMANO À EDUCAÇÃO: A INCLUSÃO DAS TEMÁTICAS DE GÊNERO E DE SEXUALIDADES NOS PLANOS DE EDUCAÇÃO
}

\section{HUMAN RIGHT TO EDUCATION: THE INCLUSION OF GENDER THEME AND SEXUALITIES IN EDUCATION PLANS}

\author{
${ }^{1}$ Renato Duro Dias \\ ${ }^{2}$ Luciana Alves Dombkowitsch
}

\section{RESUMO}

Esta pesquisa analisa a evolução das proposições que deram origem à Lei 13.005/2014, correspondente ao Plano Nacional de Educação, e em qual conjuntura política se deu a construção da possibilidade de que o mesmo fosse aprovado sem a diretriz que previa a superação das desigualdades educacionais, com ênfase na promoção da igualdade racial, regional, de gênero e de orientação sexual, tentando problematizar a cruzada ideológica que se mobilizou contra a inclusão do que chamaram de ideologia de gênero, como uma verdadeira afronta aos direitos constitucionais fundamentais, que colocam a educação no patamar de direitos humanos e como a não inclusão das discussões de gênero e de sexualidades impossibilitam sejam efetivados os princípios constitucionais garantidores da igualdade, do respeito à diversidade e da construção de uma educação pautada na solidariedade e na justiça social. Assim, dentro desta diversidade de enfoques, problematizase referenciais teóricos e metodológicos com ênfase nos estudos culturais. O estudo ora proposto se trata de um recorte de uma investigação mais ampla que objetiva mapear e discutir os campos das políticas públicas educacionais, de gênero e de sexualidades, como forma de viabilizar a efetivação da educação como direito social fundamental. Estas pesquisas de abordagem preponderantemente qualitativa terão como cerne a análise dos temas, referenciais teórico-metodológicos e filiação acadêmica de seus autores, sinalizando caminhos para futuros estudos que possibilitem uma maior interlocução entre a produção da pós-graduação e a qualidade social do ensino do direito no Brasil.

Palavras-chave: Palavras-chave: educação, Gênero, Sexualidades, Políticas públicas, Direitos humanos

\footnotetext{
1 Doutor em Educação pela Universidade Federal de Pelotas - UFPEL, Pelotas- RS (Brasil). Professor da Universidade Federal do Rio Grande - FURG, Rio Grande - RS (Brasil). E-mail: renatodurodias@ gmail.com

${ }^{2}$ Mestranda em Direito e Justiça Social na Universidade Federal do Rio Grande, FURG Rio Grande - RS (Brasil). Professora da Faculdade Anhanguera do Rio Grande/RS. (Brasil). E-mail: lucianadomb@vetorial.net
} 


\begin{abstract}
This research analyzes the evolution of the propositions that led to Law 13,005 / 2014, corresponding to the National Education Plan, and in what political context was given the construction of the possibility that it be approved without the guideline which provided for overcoming educational inequalities with emphasis on promoting racial equality, regional, gender and sexual orientation, trying to question the ideological crusade that has mobilized against the inclusion of what they called "gender ideology" as a real affront to fundamental constitutional rights, which put education in human rights and level as the non-inclusion of gender discussions and sexualities impossible to take effect guaranteeing the constitutional principles of equality, respect for diversity and the construction of a guided education on solidarity and social justice. Thus, within this diversity of approaches, it discusses-theoretical and methodological frameworks with an emphasis on cultural studies. The study proposed herein it is a fragment of a wider investigation that aims to map and discuss the fields of educational policies, gender and sexuality, in order to make possible the realization of education as a fundamental social right. These primarily qualitative approach of research will center around the analysis of the topics, theoretical and methodological frameworks and academic affiliation of the authors, signaling paths for future studies that will permit greater dialogue between the graduate production and social quality of law teaching in Brazil.
\end{abstract}

Keywords: Keywords: education, Gender, Sexualities, Public policies, Human rights 


\section{INTRODUÇÃO}

O presente trabalho tem como objetivo analisar a evolução das proposições que deram origem à Lei 13.005/2014 ${ }^{1}$, correspondente ao Plano Nacional de Educação que vigerá no Brasil no período compreendido entre os anos de 2014-2023 e qual a conjuntura política que possibilitou a aprovação do mesmo, sem que dele constasse a previsão contida no PLC - Projeto de Lei da Câmara n. ${ }^{\circ} 103 / 2012^{2}$, no qual estava previsto em seu artigo $2^{\circ}$, inciso III, que uma das diretrizes do plano nacional de ensino era a -superação das desigualdades educacionais, com ênfase na promoção da igualdade racial, regional, de gênero e de orientação sexual\| (PLC n. ${ }^{\circ}$ 103/2012).

O processo de construção dos atuais planos, nacional, distrital, estaduais e municipais não tem como ser analisado de forma desvinculada do papel exercido pela I Conferência Nacional de Educação (CONAE) ${ }^{3}$ ocorrida em 2010. Sob o tema central -Construindo o sistema nacional articulado: o plano nacional de educação, diretrizes e estratégias de açãoll, finalizou-se a edição da CONAE com um -Documento Finall, instrumento este determinante para a elaboração do PL 8035/2010 que culminou no PLC 103/2012, que após intenso combate das forças conservadoras da nossa sociedade, extirparam parte do texto que previa como uma das diretrizes do PNE a superação das desigualdades educacionais com ênfase na promoção da igualdade racial, de gênero e de orientação sexual, dando origem à lei 13.005/2014.

A inserção da referida diretriz desencadeou uma verdadeira cruzada liderada pelos setores conservadores das igrejas católica e evangélica, especialmente as neopentecostais. Um exemplo é a nota ${ }^{4}$ emitida pela Conferência Nacional dos Bispos do Brasil (CNBB) -alertandoll a sociedade sobre os -perigos\| da inserção do que designaram de -ideologia de gêneroll nos planos de educação, ignorando o processo democrático em que se deu a elaboração do documento final da Conferência Nacional de Educação, levianamente

\footnotetext{
1 A Lei 13.005 foi sancionada pela presidência da república em 25/06/2014, aprovando o Plano Nacional de Educação - PNE, com vigência por 10 (dez) anos, a contar da data da sua publicação em cumprimento ao disposto no artigo 214 da Constituição Federal.

2 O projeto de lei da câmara n. ${ }^{\circ}$ 103/2012 remetido ao senado federal deu origem, depois de várias alterações, à Lei 13.005/2014.

3 A I Conferência Nacional de Educação aconteceu em Brasília, entre os dias 28 de março e $1^{a}$ de abril de 2010 e teve como pauta o tema: Construindo um Sistema Nacional Articulado de Educação: Plano Nacional de Educação, suas Diretrizes e Estratégias de Ação, tendo sido precedida de Conferências Municipais, ocorridas no primeiro semestre de 2009 e de Conferências Estaduais e do Distrito Federal, ocorridas no segundo semestre do mesmo ano, conforme informações obtidas através do sítio www.conae.mec.gov.br.

4 Trata-se da nota n. ${ }^{\circ}$ 325/15 emitida pela Presidência da Conferência Nacional dos Bispos do Brasil, consultada através do sítio www.cnbb.org.br.
} 
afirmando em sua nota, que o processo de inclusão da diretriz de discussão de gênero e de sexualidades se dera de forma silenciosa.

A cruzada então iniciada, rejeitando a discussão de gênero e de sexualidades em todos os níveis da educação nacional, faz parte de um projeto ideológico voltado, como diz Butler (2014) para a manutenção das práticas sociais consolidadas em um processo de naturalização dos corpos dentro de uma concepção binária dos gêneros, a qual estabelece como possibilidade única de existência dos sexos, qual seja, o masculino e o feminino, os quais são tidos como naturais e assim, consequentemente criam os corpos que não tidos como não naturais, não humanos, visto que construídos fora do padrão heteronormativo vigente.

Ademais, a manutenção desse padrão heteronormativo constituído dentro da concepção binária dos gêneros (SCOTT, 1995), coloca sempre um deles em situação de superioridade em relação ao outro. Atribuindo adjetivações incluem uns e excluem outros, como por exemplo, a emoção normalmente atribuída à mulher, assim como a razão atribuída ao homem, assim como a sensibilidade é um adjetivo feminino, à virilidade é um adjetivo masculino. Dentro desse padrão, além de se excluir os corpos que não se enquadram nele colocando-os na zona de abjeção (BUTLER, 2014), constrói-se uma sociedade onde o feminino se encontra em subordinação ao masculino, criando uma verdadeira hierarquia entre os sexos, onde às mulheres cabe o papel de subalternidade, perpetuando assim, uma sociedade androcentrista e heteronormativa.

Em uma sociedade androcentrista e heteronormativa, de corpos rígidos e inflexíveis da construção social identitária, produz-se uma insensata exclusão social. Na escola encontramse múltiplas possibilidades de corpos trans, híbridos, plurais e identidades de gênero não compartimentadas nas caixas pré-estabelecidas para o que é tradicionalmente construído (constituído e naturalizado) como corpo masculino e feminino.

A rigidez deste constructo identitário é um dos indiciários que se insere no discurso médico: -é um meninoll, -é uma meninall. A produção de significações que se traduz a partir deste discurso faz gerar uma inevitável e desastrosa sequência de novos discursos e práticas que acabam enjaulando/aprisionando o corpo a uma única e admissível performatividade.

Deste discurso derivam múltiplas práticas de controle social sobre este corpo.

Os corpos ganham sentido socialmente. A inscrição dos gêneros — feminino ou masculino - nos corpos é feita, sempre, no contexto de uma determinada cultura e, portanto, com as marcas dessa cultura. As possibilidades da sexualidade — das formas de expressar os desejos e prazeres - também são sempre socialmente estabelecidas e codificadas. As identidades de gênero e sexuais são, portanto, compostas e definidas por relações sociais, elas são moldadas pelas redes de poder de uma sociedade. (LOURO, 2000, p.10) 
Foucault (2013), em A ordem do discurso, adverte para as interdições discursivas que nos impedem de falar de tudo em qualquer circunstância e que, portanto, geram um ritual de negação.

\begin{abstract}
Notaria apenas que, em nossos dias, as regiões onde a grade é mais cercada, onde os buracos negros se multiplicam, são as regiões da sexualidade e as da política: como se o discurso, longe de ser esse elemento transparente ou neutro no qual a sexualidade se desarma e a política pacífica, fosse um dos lugares onde elas exercem, de modo privilegiado, alguns de seus mais temíveis poderes. (FOUCAULT, 2013, p. 09)
\end{abstract}

Por outra parte, a Constituição Federal estabelece em seu artigo $6^{\circ}$ que a educação é um direito de todos e dever do Estado, direito este ligado ao reconhecimento da dignidade da pessoa humana, bem como, seus objetivos estão diretamente relacionados à efetivação dos Direitos Humanos, quais sejam, a construção de uma sociedade livre, justa, solidária, comprometida com a erradicação da pobreza, da marginalidade e das desigualdades sociais. Ao Estado cabe o papel de elaboração e de implementação de políticas públicas que concorram para a justiça social, considerando a inclusão, a diversidade e a igualdade como forma de garantir tais políticas.

Neste contexto, as discussões de gênero e de sexualidades nos Planos de Educação são determinantes para que se consolidem os princípios constitucionais que determinam que a educação será promovida e incentivada com a colaboração da sociedade, visando a democratização do acesso, da permanência e do sucesso escolar, visando assim, o pleno desenvolvimento da pessoa e seu preparo para o exercício da cidadania, nos termos do artigo 205 da CF/88.

\title{
2. O PROCESSO DE CONSTRUÇÃo dOS PlanOS NACIONAL, DiSTRITAL, ESTADUAIS E MUNICIPAIS DE EDUCAÇÃO
}

Inicialmente é importante contextualizar o processo de constituição do atual plano nacional de educação, o qual teve sua construção a partir da I Conferência Nacional de Educação - CONAE, realizada no período de 28 de março a $1^{\circ}$ de abril de 2010 , que em parceria com os diversos sistemas de ensino, órgãos educacionais, Congresso Nacional e sociedade civil que se mobilizaram em conferências municipais, estaduais e distrital, debateram sobre o tema central da conferência: Construindo o Sistema Nacional Articulado: O Plano Nacional de Educação, Diretrizes e Estratégias de Ação. 
O resultado do intenso debate que se seguiu após a realização das conferências nacional, estaduais, municipais e distrital é base do documento denominado de Documento Final $^{5}$, no qual estão apresentadas as diretrizes, metas e ações para a política nacional de educação, na perspectiva da inclusão, igualdade e diversidade, o que se constituiu como um marco histórico para a educação brasileira na contemporaneidade. Pode-se dizer então, que o Documento Final resultou de um rico processo de construção coletiva, desencadeado pela decisão política de submeter ao debate social as ideias e proposições em torno da construção do Sistema Nacional de Educação, que assegurasse a articulação entre os entes federados e os setores da sociedade civil.

Dessa maneira foram lançadas as bases para a concretização do artigo 214 da Constituição Federal de 1988, o qual prevê que a lei estabelecerá o plano nacional de educação, de duração decenal, com o objetivo de articular o sistema nacional de educação em regime de colaboração e definir diretrizes, objetivos, metas e estratégias de implementação para assegurar a manutenção e desenvolvimento do ensino em seus diversos níveis, etapas e modalidades por meio de ações integradas dos poderes públicos das diferentes esferas federativas.

O Documento Final buscou apresentar uma proposta que diz respeito a formação de uma educação democrática pautada na justiça social através da superação de desigualdades sociais de classe, étnico-raciais, de gênero e de sexualidades e que reconheça e dialogue com a diversidade, ampliando a noção de inclusão e de igualdade social, através da democratização do acesso, da permanência e do sucesso escolar, uma vez que, a constituição federal incluí a Educação como direito humano fundamental.

No entanto, mesmo tendo a Conferência Nacional de Educação aprovado como eixo temático do Sistema Nacional de Educação a garantia da introdução da discussão de gênero, identidade de gênero, orientação sexual, diversidade sexual e educação sexual, como disciplinas obrigatórias, no currículo da formação inicial e continuada, nas atividades de ensino, pesquisa e extensão, nas licenciaturas e bacharelado, na pós-graduação, no ensino fundamental e médio, em todas as áreas do conhecimento, de forma interdisciplinar, transdisciplinar e transversal, articulando-os à promoção dos direitos humanos, meta do Plano

\footnotetext{
5 O Documento Final corresponde ao resultado da I Conferência Nacional de Educação - CONAE, no qual ficaram consolidadas diretrizes, metas e ações para a política nacional de educação, na perspectiva da inclusão, igualdade e diversidade, o que se constitui como marco histórico para a educação brasileira na contemporaneidade, o qual pode ser consultado no sítio http://conae.mec.gov.
} 
Nacional de Educação em Direitos Humanos, o Projeto de Lei 8035/2010 ${ }^{6}$ não correspondeu à referida meta.

Após amplo debate na Câmara dos Deputados, é que se obteve a conquista almejada, vez que o Projeto de Lei da Câmara n. ${ }^{\circ}$ 103/2012, enviado ao Senado Federal, incluiu nas diretrizes do PNE a -superação das desigualdades educacionais, com ênfase na promoção da igualdade racial, regional, de gênero e de orientação sexual;\| No entanto, após vários substitutivos, o Senado Federal aprova a Lei 13.005/2014 com outra redação qual seja: -superação das desigualdades educacionais, com ênfase na promoção da cidadania e na erradicação de todas as formas de discriminação;", retirando do texto às referências à igualdade de gênero e de sexualidades, tendo a referida Lei sido promulgada pela presidenta da república, que cooptou aos movimentos mais conservadores da sociedade.

Em junho de 2015, a Assembléia Legislativa do Estado do Rio Grande do Sul, aprova o Plano Estadual de Educação sem fazer menção ao ensino sobre identidade de gênero, embora tal referência estivesse no texto original do projeto de Lei. Nesse mesmo sentido, a maioria dos Municípios do Estado do Rio Grande do Sul, tiveram aprovados seus Planos Municipais de Educação, sem que fizessem referência a -superação das desigualdades educacionais, com ênfase na promoção da igualdade de gênero e de orientação sexual;॥

\section{A REJEIÇÃO DA INCLUSÃO DOS TEMAS SOBRE GÊNERO E SEXUALIDADES NOS PLANOS DE EDUCAÇÃO}

A maioria dos setores conservadores da sociedade civil se uniram em uma cruzada contra o que denominaram de -ideologia de gêneroll na educação e impuseram uma perda significativa aos processos democráticos, retirando do Plano Nacional de Educação o texto que definia como uma das diretrizes da Educação Nacional a superação das desigualdades educacionais, com ênfase na promoção da igualdade racial, regional, de gênero e de orientação sexual, perda esta que se seguiu em muitos estados brasileiros, assim como em relação a uma gama enorme de municípios, que também aprovaram seus planos municipais sem a previsão de inclusão em todos os níveis de educação das questões relativas à gênero e às sexualidades.

Nesse contexto, merece referência o papel do Conselho Permanente da Conferência Nacional dos Bispos do Brasil (CNBB), que reunido, aprovou e divulgou nota a respeito da

\footnotetext{
6 O projeto de Lei 8035/2010, foi o projeto que deu origem ao Projeto de Lei da Câmara 103/2012 e que consequentemente originou a Lei 13.005/2014, correspondente ao PNE do decêndio 2014-2023.
} 
inclusão da ideologia de gênero nos textos em discussão para os Planos Municipais de educação, afirmando categoricamente, que a introdução desta ideologia na prática pedagógica das escolas -traria consequências desastrosas para a vida de crianças, de adolescentes e das famílias, e, assim, pontuando o debate a partir de dogmas judaico-cristãos que violam a livre expressão das sexualidades e, também, da afetividade.ll (nota 325/15 CNBB)

Essa nota emitida pela CNBB foi encaminhada a todos os municípios do Brasil no intuito de retirar dos textos dos Planos Municipais de Educação a diretriz relativa a superação das desigualdades educacionais, com ênfase na promoção da igualdade de gênero e de sexualidades o que consequentemente causou uma reação dos movimentos feministas e LGBTQs, provocando grandes enfrentamentos em muitas câmaras municipais.

O resultado final deste embate, pelo menos para os próximos dez anos, restou claro, foi o retrocesso para o que se pretendia denominar uma educação inclusiva, democrática e respeitadora das diferenças, representando um entrave no que se refere ao direito humano à educação. Ao contrário destes obstáculos percebidos, defende-se a inclusão da discussão de gênero e de sexualidades em todos os níveis de educação, pois representa uma forma de assegurar que todos os espaços escolares sejam um espaço pedagógico livre e seguro, que garantam inclusão, qualidade de vida, liberdade de expressão e promoção dos direitos humanos, ampliando e democratizando o acesso à educação.

\section{A CONSTRUÇÃO DEMOCRÁTICA DO DOCUMENTO FINAL DAS CONFERÊNCIAS NACIONAL, DISTRITAL, ESTADUAIS E MUNICIPAIS DE EDUCAÇÃO}

O ano de 2009 se caracterizou por um período no qual uma grande parceria se estabeleceu entre os mais variados sistemas de ensino, os órgãos educacionais, o Congresso Nacional e a sociedade civil. Esta parceria se constituiu em um fator determinante para a mobilização de amplos setores da sociedade, especialmente os trabalhadores da educação, que se mobilizaram nas conferências municipais ou intermunicipais e nas conferências estaduais e do Distrito Federal, gerando a construção ainda, de vários outros espaços de debate acerca do tema central da Conferência Nacional de Educação - CONAE: Construindo o Sistema Nacional Articulado: O Plano Nacional de Educação, Diretrizes e Estratégias de Ação. 
O resultado desse processo de mobilização e debate sobre a educação brasileira está consolidado no que se denominou de Documento Final, o qual apresenta as diretrizes, as metas e as ações para a política nacional de educação, na perspectiva da inclusão, igualdade e diversidade, o que se constitui como marco histórico para a educação brasileira, assim, podemos dizer que o Documento Final resultou de um rico processo de construção coletiva, desencadeado pela decisão política de submeter ao debate social as idéias e proposições em torno da construção do Sistema Nacional de Educação, que assegurasse a articulação entre os entes federados e os setores da sociedade civil.

O Documento-Referência Construindo o Sistema Nacional Articulado de Educação: O Plano Nacional de Educação, Diretrizes e Estratégias de Ação serviu de base consistente para as discussões coordenadas pela Comissão Organizadora Nacional, constituída por representação do governo e da sociedade civil, em todo o território nacional. Esse documento se propunha a examinar a situação educacional brasileira e suas perspectivas, tendo por base os diferentes níveis e modalidades de educação, sob a ótica da qualidade e valorização da educação. Ele foi objeto de debates, estudos e de deliberações pela Comissão Nacional, acrescido de novas proposições, pelas emendas que emergiram ao longo das discussões nos estados, Distrito Federal e municípios, sendo analisadas e aprovadas na Conferência Nacional de Educação.

Portanto, se configura inaceitável a argumentação utilizada pela presidência da Conferência Nacional dos Bispos do Brasil CNBB, que através da nota n..$^{\circ}$ 0325/15 ${ }^{7}$ de que a introdução de uma política de superação das desigualdades educacionais com ênfase na promoção da igualdade de gênero e de orientação sexual tenha sido inserida de forma silenciosa como uma das diretrizes dos planos municipais de educação, como se pode observar do trecho da referida nota, que segue:

O mais grave é que se quer introduzir esta proposta de forma silenciosa nos Planos Municipais de Educação, sem que os maiores interessados, que são os pais e educadores, tenham sido chamados para discuti-la. A ausência da sociedade civil na discussão sobre o modelo de educação a ser adotado fere o direito das famílias de definir as bases e as diretrizes da educação que desejam para seus filhos. (CNBB, nota $0325 / 15)$

\footnotetext{
7 A Conferência nacional dos Bispos do Brasil - CNBB emitiu a Nota 325/15 em ato de oposição a inserção das discussões de gênero de orientação sexual nos planos municipais de educação.
} 
De forma alguma a introdução desta política como uma das diretrizes dos planos municipais de educação se deu de forma silenciosa, ao contrário, foi fruto de um amplo debate nacional, que envolveu amplamente todos os estados da federação e de seus municípios, no qual participaram os mais diversos setores da sociedade, em especial aqueles ligados diretamente com a educação, refletindo-se, o que se consolidou no Documento Final o qual, foi determinante na elaboração dos Planos Municipais de Educação.

\section{A EDUCAÇÃO COMO DIREITO SOCIAL FUNDAMENTAL}

$\mathrm{O}$ artigo $6^{\circ}$ da Constituição Federal estabelece que são direitos sociais a educação, a saúde, a alimentação, o trabalho, a moradia, o lazer, a segurança, a previdência social, a proteção à maternidade e à infância, além da assistência aos desamparados. O direito à educação, previsto na Constituição Federal de 1988, está ligado ao reconhecimento da dignidade da pessoa humana, bem como, seus objetivos estão diretamente relacionados à efetivação dos Direitos Humanos, quais sejam, a construção de uma sociedade livre, justa, solidária, comprometida com a erradicação da pobreza, da marginalidade e das desigualdades sociais.

Art. $6^{\circ}$ São direitos sociais a educação, a saúde, a alimentação, o trabalho, a moradia, o lazer, a segurança, a previdência social, a proteção à maternidade e à infância, a assistência aos desamparados, na forma desta Constituição. (CF/88)

O Constituinte Federal, indo ao encontro de seus princípios fundamentais, incluiu a Educação no Capítulo III do Título VIII, correspondente à Ordem Social, que tem como objetivo o bem estar e a justiça social, estabelecendo que o Estado tem o papel primordial na promoção da educação, elaborando políticas públicas que concorram para a justiça social, considerando a inclusão, a diversidade e a igualdade como forma de garantir tais políticas.

Art. 193. A ordem social tem como base o primado do trabalho, e como objetivo o bem-estar e a justiça sociais. $(\mathrm{CF} / 88)$

A explicitação do dever do Estado no art. 208, somada aos mecanismos jurídicos presentes na atual Constituição, instrumentalizou o direito à educação de forma marcante a partir de 1988. No entanto, as discussões de gênero, diversidade sexual e orientação sexual são determinantes para que se consolidem outros princípios constitucionais, como aqueles que determinam que a educação será promovida e incentivada com a colaboração da sociedade, 
visando ao pleno desenvolvimento da pessoa e seu preparo para o exercício da cidadania, nos termos do artigo 205 da $\mathrm{CF} / 88$.

Art. 205. A educação, direito de todos e dever do Estado e da família, será promovida e incentivada com a colaboração da sociedade, visando ao pleno desenvolvimento da pessoa, seu preparo para o exercício da cidadania e sua qualificação para o trabalho. $(\mathrm{CF} / 88)$

Ademais, para a concretização de tais princípios fundamentais o artigo 206, da Constituição Federal, estabeleceu que o ensino será ministrado com base nos princípios da igualdade de condições para o acesso e permanência na escola, da liberdade de aprender, ensinar, pesquisar e divulgar o pensamento, a arte e o saber e do pluralismo de ideias e de concepções pedagógicas.

\footnotetext{
Art. 206. O ensino será ministrado com base nos seguintes princípios: I - igualdade de condições para o acesso e permanência na escola;

II - liberdade de aprender, ensinar, pesquisar e divulgar o pensamento, a arte e o saber;

III - pluralismo de idéias e de concepções pedagógicas, e coexistência de instituições públicas e privadas de ensino;

[...] $(\mathrm{CF} / 88)$
}

É nesse contexto, que se insere o Sistema Nacional de Educação, que tem como base o Plano Nacional de Educação e os Planos Estaduais e Municipais de Educação, aptos a constituírem mecanismos de elaboração e de implementação de políticas públicas educacionais capazes de tornarem eficaz o princípio constitucional de justiça social, promovendo uma educação, em todos os seus níveis, que tenha como eixo a inclusão, a diversidade e a igualdade.

A sociedade brasileira, marcada por profundas desigualdades sociais de classe, étnicoracias, de gênero e de sexualidades, somente alcançará uma educação pautada na justiça social se reconhecer e dialogar com a diversidade, ampliando assim, a noção de inclusão e de igualdade social capazes de consolidar a democratização de acesso, de permanência e de sucesso escolar através de políticas públicas que articulem educação e direitos humanos não hegemônica, mas que reconheça a diversidade.

Essa articulação, segundo Seffner (2011), nos leva a pensar uma escola que precisa se organizar em base nos princípios dos direitos humanos, quais sejam, aqueles direitos relacionados de modo direto com a dignidade da pessoa humana. Direitos que permitam a um indivíduo, mesmo sendo minoria, ser respeitado e desfrutar das mesmas oportunidades na 
vida que os demais. Os direitos humanos são o instrumento que não permite que as maiorias possam hostilizar as minorias, como tem sido infelizmente frequente na nossa história.

\section{A INTRODUÇÃO DA DISCUSSÃO DE GÊNERO E DE DIVERSIDADE SEXUAL NOS PLANOS DE EDUCAÇÃO COMO GARANTIA DE EFETIVIDADE DE POLÍTICAS PÚBLICAS EDUCACIONAIS DE INCLUSÃO}

A introdução da discussão de gênero e de sexualidades nos planos de educação como meio de superação das desigualdades educacionais, com ênfase na promoção da igualdade de gênero e de sexualidades é medida que se faz imprescindível para a concretização de uma política educacional voltada para o combate do preconceito e da discriminação de pessoas lésbicas, gays, bissexuais, travestis e transexuais e das mulheres, através de um discurso de superação da dominação do masculino sobre o feminino, na construção de uma educação não sexista e sem homofobia.

É sabido que historicamente a escola produz e reproduz, diferenças, distinções e desigualdades, separando os sujeitos, -tornando aqueles que nela entravam distintos dos outros, os que a ela não tinham acesso.॥ (LOURO, 2014, p. 61), tendo um papel determinante também na divisão daqueles que nela se encontravam, criando inúmeros sistemas de classificação e hierarquização. Louro (2014) exemplifica esta divisão como aquela ocorrida em função da classe social, dividindo ricos e pobres, aquela decorrente de religião, dividindo católicos e protestantes e teve ainda um papel determinante na separação de meninos e de meninas.

Neste sentido, podemos dizer que a escola e seus programas político-pedagógicos foram pensados para alunos de classe média urbana, brancos, católicos, em geral do gênero masculino, e certamente heterossexuais, oriundos de famílias com escolaridade elevada. No entanto, novos grupos, até então não acolhidos, passaram a ocupar espaço nesta escola, reivindicando o espaço que até então lhes haviam sido negado. Para Louro (2014), esses novos grupos impuseram muitas transformações nos sistema educacional até então vigente, mas muitas mudanças ainda hão de ser implementadas para que se possa garantir uma educação democrática.

A escola, ainda hoje, é um espaço de exclusão, delimitando e constituindo sujeitos, informando o que cada um deles pode e não pode fazer, construindo através do discurso o lugar de menino e o lugar de menina, delimitando papéis ao que corresponde às feminilidades 
e às masculinidades. Para Butler (2014), essa forma de representação binária dos gêneros, além de constituir relações de hierarquia, onde o feminino se encontra subordinado ao masculino, delimita os corpos dentro de uma padrão heteronormativo, padrão este que orienta as relações sociais, excluindo outras sexualidades que não aquela constituída dentro do padrão binário heteronormativo.

Assim, podemos dizer que a escola também reproduz o padrão binário $\mathrm{e}$ heteronormativo, segundo os quais as performances corporais que se constroem fora desse padrão dito como natural, como a única forma permitida de expressão da sexualidade acaba por confirmar os que ficam excluídos dessa concepção, configurando o que diz Butler (2014) a zona de rejeição, de abjeção social, ficando todos os corpos que estão fora desse padrão na categoria de desumanizados.

Para Seffner (2011), algumas diferenças culturais são mais facilmente aceitas na escola, embora possam trazer problemas e gerar mais trabalho para os professores, como por exemplo os alunos portadores de necessidades especiais, no entanto, o mesmo não ocorre com aqueles alunos e alunas que manifestam diferenças em relação ao padrão que se espera normal, qual seja o heterossexual, que exige o cumprimento e a manutenção de estereótipos típicos e inconfundíveis de ser menino ou menina conforme o sexo verificado ao nascer, qual seja, o de interessar-se pelo sexo oposto ao seu.

Como já referido anteriormente, em nossa sociedade as identidades de gênero e de sexualidades ocupam lugar preponderante no que se refere à definição de um status de humanidade, normalmente relacionadas à ideia de culpa do sujeito que se apresenta diferente em relação ao padrão heteronormativo. Seffner (2011) traz algumas considerações sobre o que é considerado tolerável: -Podemos tolerar alguns desvios e borramentos de conduta, de origem social, de cor da pele, mas indefinições e atravessamentos no que se espera em termos de performance sexual ou de gênero resultam em fortes sentimentos de abjeção.l (SEFFNER, 2011, p. 110).

Neste caso, na maioria das vezes os alunos e alunas que assim se manifestam, aparecem como agentes desse -desvioll, sendo vistos em geral, como aqueles que -não merecem\| ser incluídos. Assim, é possível verificar, que a dita inclusão está diretamente relacionada ao fato de o aluno ou a aluna comportarem-se conforme os padrões esperados de comportamentos de gênero e sexualidade, caso contrário, segundo Seffner (2011), serão hostilizados o que consequentemente lhes acarretará claros e evidentes prejuízos em seu desempenho escolar, fato que em muitas ocasiões é o responsável pela evasão escolar. 
Seffner (2011) nos apresenta ainda, alguns discursos recorrentes, extraídos das vivências diárias dos espaços escolares, é além de possível, comum ouvirmos discursos constituídos no preconceito e de intolerância, tais como:

[...] eu sinto nojo quando vejo dois homens se beijandoll ou algo como -me dá nojo quando vejo aquelas duas gurias de mãos dadas na hora do recreioll. Junte-se a isso outra particularidade. As performances de gênero e sexualidade que se afastam da norma esperada são sempre vistas como produto de uma ação deliberada do indivíduo, em frases do tipo -não sei por que ela se veste assim meio como um menino, porque ela não se veste como uma menina?\| ou então -porque ele precisa falar daquele jeito mais afeminado? Porque não fala como homem? (SEFFNER, 2011, p. 110-111)

São esses discursos que constituem práticas preconceituosas e intolerantes, e se queremos ter uma escola que não produza preconceitos, que não estimule e não permita a discriminação temos que, a partir de uma atitude ativa do Estado, se implementem políticas públicas capazes de promover a superação das desigualdades educacionais, com ênfase na promoção da igualdade de gênero e de sexualidades, o que somente será possível com a elaboração de Planos de Educação que incluam em todos os níveis de educação as discussões sobre gênero e sexualidades, abrindo espaço para a consolidação de uma -[...] escola multigênero, multicultural, multirracial, multisexual, multifamiliar, multireligiosa, etc.ll (SEFFNER, 2011, p. 111)

\section{CONSIDERAÇÕES FINAIS}

O presente trabalho se propôs problematizar o espaço e o contexto social e conjuntural em que se deu a Construção do Sistema Nacional Articulado: O Plano Nacional de Educação, Diretrizes e Estratégias de Ação, assim como dos Planos Estaduais, Municipais e Distrital de educação concluídos no ano de 2015. Inicialmente se buscou resgatar os passos do processo de construção desse sistema nacional de educação, que teve origem a partir do amplo debate que precedeu e sucedeu a realização da I Conferência Nacional de Educação realizada no ano de 2010.

O resultado deste processo amplamente democrático, realizado com a participação de diversos setores da sociedade interessados na educação, resultou na elaboração do que se denominou Documento Final, no qual foram estabelecidas as diretrizes, metas e ações para a política nacional de educação, dentro de uma perspectiva de inclusão, igualdade e diversidade, 
lançando as bases para a concretização do artigo 214 da Constituição Federal que determina que a lei estabelecerá o plano nacional de educação, de duração decenal.

O Documento Final apresentou à sociedade uma proposta a respeito da formação de uma educação democrática, inclusiva, pautada no princípio de justiça social para a superação de desigualdades sociais de gênero e de sexualidades, assim como de classe e de origem étnicoraciais capazes de proporcionarem a democratização do acesso, da permanência e do sucesso escolar, efetivando a educação como direito humano fundamental através da garantia da introdução das discussões de gênero e de sexualidades em todos os níveis da educação nacional.

O processo de aprovação do Plano Nacional de Educação, iniciou-se com o projeto de Lei 8.035/2010, que inicialmente não teve em seu texto a inserção da diretriz referente a -superação das desigualdades educacionais com ênfase na promoção da igualdade racial, regional, de gênero e de orientação sexualll, tendo sido esta diretriz incorporada apenas no Projeto de Lei da Câmara 103/2012, no entanto a cruzada contra a inserção da -ideologia de gêneroll nas escolas, fez com que o processo democrático experimentasse uma perda significativa, com a retirada da referida diretriz do texto aprovado e transformado na Lei 13.005/2014 - Plano Nacional de Educação.

A cruzada intentada por alguns setores da sociedade e encabeçada pelos setores mais conservadores das igrejas católicas e evangélicas, em especial pelas neopentecostais, prosseguiu no ano de 2015, pela não inclusão da diretriz referente a -superação das desigualdades educacionais com ênfase na promoção da igualdade racial, regional, de gênero e de orientação sexualll nos planos estaduais e municipais de educação. A Conferência Nacional dos Bispos do Brasil emitiu uma nota afirmando categoricamente, que a introdução da ideologia de gênero na prática pedagógica das escolas traria consequências desastrosas para a vida das crianças e das famílias, rejeitando as discussões acerca das identidades de gênero e de sexualidades.

Temos então, que a retirada da diretriz correspondente a -superação das desigualdades educacionais com ênfase na promoção da igualdade racial, regional, de gênero e de orientação sexualll dos planos estaduais e municipais de educação, assim como já havia sido feito relativamente ao plano nacional de educação afronta a constituição federal que determinada ser direito de todos e dever do estado a implementação de políticas públicas capazes de garantirem a todos uma educação de democrática, inclusiva, ademais, pautada nos princípios de solidariedade e de justiça social.

A retirada dos planos de educação da obrigatoriedade de inserção das discussões acerca de gênero e de sexualidades em todos os níveis educacionais proporciona que se perpetue 
a invisibilidade das violências praticadas em razão de atos de homofobia e de misoginia, construídos a partir de uma cultura androcentrista e heteronormativa. Através das pesquisas a que se propôs o presente trabalho, foi possível problematizar o papel da escola na produção e na reprodução destas práticas.

A escola historicamente produziu e reproduziu diferenças, distinções e desigualdades, normatizando sujeitos dentro de um padrão heteronormativo constituído dentro e uma oposição binária dos gêneros, que somente constitui como normal os corpos que se constituem dentro desse padrão (feminino/masculino), colocando todos os demais, ou seja, aqueles que não se enquadram dentro deste padrão em uma zona chamada de abjeção, separando os corpos humanos, ditos naturais, dos desumanos, não naturais.

Desta forma, se conclui que somente com a introdução da discussão de gênero e de diversidade sexual nos planos de educação será possível a superação das desigualdades educacionais, promovida pela igualdade de gênero e de orientação sexual. Essa medida é imprescindível para a concretização de uma política pública de educação voltada para o combate do preconceito e da discriminação de pessoas lésbicas, gays, bissexuais, travestis e transexuais e das mulheres, através de um discurso de superação da dominação do masculino sobre o feminino, na construção de uma educação não sexista e sem homofobia.

\section{REFERÊNCIAS BIBLIOGRÁFICAS}

BENTO, Berenice Alves de Melo. O que é transexualidade. São Paulo: Brasiliense, 2008. BRASIL. Constituição da República Federativa do Brasil. Disponível em: http://www.planalto.gov.br. Acesso em julho de 2015.

. Lei 13.005/2014. Plano Nacional de Educação. Disponível em:

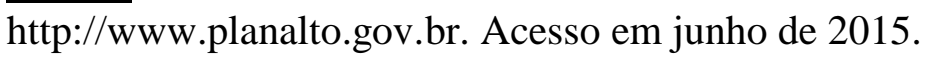

Ministério da Educação e Cultura. Conferência Nacional de Educação. Documento Final. Disponível em: http://conae.mec.gov.br. Acesso em julho de 2015.

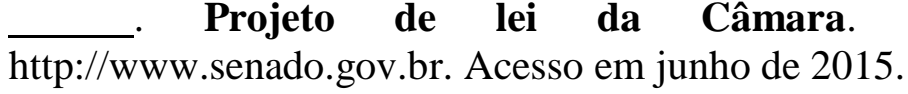

BUTLER, Judith. Problemas de gênero: Feminismo e subversão da identidade. $7^{\mathrm{a}}$ ed. Rio de Janeiro: Civilização Brasileira, 2014.

CNBB. Conferência Nacional dos Bispos. Notas e Declarações. Nota n. ${ }^{\circ}$ 325/2015. Disponível em: http://www.cnbb.org.br. Acesso em julho de 2015. 
FOUCAULT, Michel. A Ordem do Discurso. 23ª ed. São Paulo: Edições Loyola, 2013.

Terra, 2014

Michel. História da Sexualidade 1: A vontade de saber. $1^{\text {a }}$ ed. São Paulo: Paz e , Michel. Microfísica do Poder. $2^{\mathrm{a}}$ ed. Rio de Janeiro: Paz e Terra, 2015.

, Michel. Vigiar e Punir. 42ª ed. Petrópolis, RJ: Vozes, 2014.

FRASER, Nancy. Da redistribuição ao reconhecimento? Dilemas da Justiça na era Póssocialista. (Org.:) SOUZA, Jessé. In: Democracia hoje: novos desafios para a teoria democrática contemporânea. Brasília: Editora Universidade de Brasília, 2001.

GOMES, Maria Tereza Uille. Direito Humano à Educação e Políticas Públicas. Curitiba: Juruá, 2009.

GONÇALVES, Leonardo A. Direitos sociais. Cidadania, política e justiça. Rio de Janeiro: Sinergia, 2013.

KROHLING, Aloísio. Direitos Humanos Fundamentais: diálogo intercultural e democracia. São Paulo: Paulus, 2009.

LOURO, Guacira Lopes. A Construção Escolar das diferenças. In: Gênero, sexualidade e educação. Uma Perspectiva pós-estruturalista. 16ª Ed. Petrópolis: Editora Vozes, 2014.

Guacira Lopes; FELIPE, Jane; GOELLNER, Silvana Vilodre. (Orgs). Corpo, Gênero e Sexualidade: Um debate contemporâneo na educação. $9^{\mathrm{a}}$ ed., Rio de Janeiro: Vozes, 2013.

, Guacira Lopes (organizadora). O Corpo Educado: Pedagogias da sexualidade. LOURO, Guacira Lopes; WEEKS, Jeffrey; BRITZMAN, Deborah; HOOKS, Bell; PARKER, Richard; BUTLER, JuditH. Traduções: Tomaz Tadeu da Silva. $2^{\mathrm{a}}$ ed., Belo Horizonte: Autêntica, 2000.

LUCAS, Doglas Cesar. Direitos Humanos e Interculturalidade: um diálogo entre a igualdade e a diferenças. 2a ed., Ijuí, RS: Editora Unijuí, 2013.

NARDI, Henrique Caetano; SILVEIRA, Raquel da Silva e MACHADO, Paula Sandrini. (Orgs.). Diversidade Sexual, Relações de Gênero e Políticas Públicas. Porto Alegre: Sulina, 2013.

PIOVESAN, Flávia. Temas de Direitos Humanos. $7^{a}$ ed. São Paulo: Saraiva, 2014.

SALIH, Sara. Judith Butler e a Teoria Queer. Belo Horizonte: Autêntica, 2013.

SANTOS, Boaventura de Sousa. Pela Mão de Alice: O Social e o Político na PósModernidade. 14 ${ }^{\mathrm{a}}$ ed., São Paulo: Cortez, 2013.

SANTOS, Boaventura de Sousa (Org.). Reinventar a Emancipação Social: Para Novos Manifestos (volume 3). Reconhecer para Libertar: os caminhos do cosmopolitismo multicultural. Porto: Edições Afrontamento, 2004. 
Boaventura de Sousa; CHAUI, Marilena. Direitos Humanos, Democracia e Desenvolvimento. São Paulo: Cortez, 2013.

SARLET, Ingo Wolfgang. Dignidade da Pessoa Humana e Direitos Fundamentais. 9a Ed. Porto Alegre: Livraria do Advogado, 2012.

SCOTT, Joan Wallach. Gênero: uma categoria útil de análise histórica. Educação \& Realidade, vol. 20, n. 2. Porto Alegre: jul-dez.1995, pp. 71-99.

SEFFNER, Fernando. Escola para todos: mesmo para aqueles que manifestam diferenças em sexo e gênero? In: SILVA. Fabiane Ferreira; MELLO. Elena Maria Billig (Orgs.). Corpos, gêneros, sexualidades e relações étnico-raciais na educação [recurso eletrônico]. Uruguaiana: UNIPAMPA, 2011.

SILVA, Tomáz Tadeu da. Documentos de Identidade: Uma introdução às teorias do currículo. Belo Horizonte: Autêntica, 1999. Vozes, 1994.

Tomáz Tadeu da. O Sujeito da Educação: estudos foucaultianos. Petrópolis, RJ:

WARAT, Luis Alberto Epistemologia e ensino do direito: o sonho acabou. Coordenadores Orides Mezzaroba, Arno Dal Ri Júnior, Aires José Rover e Cláudia Servilha Monteiro. Florianópolis: Fundação Boiteux, 2004. 